DOI: $10.5216 /$ racs.v4.58356

\title{
Pesca coletiva com timbó do povo Karajá
}

Daniel Bidjawari Karajá ${ }^{1}$

RESUMO

$\mathrm{O}$ artigo tem como base o conhecimento oral que se fundamenta em mito, história e acontecimento que revelam vários conhecimentos, envolvendo a realidade vivida por meu povo. Este trabalho é fruto de uma pesquisa que envolve o povo Karajá, em geral, Karajá do norte e Karajá do sul, e aborda a pesca coletiva com timbó do povo Karajá, iny axina. Aborda assuntos que envolvem a pescaria, em geral, como rezas, rituais, cerimonia e resguardo, principalmente o conceito de pesca dentro do ciclo que esse povo segue, cada pesca no seu devido tempo. O sucesso dessa pesca depende da organização, liderança perante esse acontecimento, tem como apoio o chefe da aldeia que também tem participação importante, nesse acontecimento, na comunidade Karajá.

PALAVRAS-CHAVE: Pescaria. Reza. Tradição. Timbó.

\section{Iny axina}

\section{TURYBÉNABUTÈ}

Waõmysỹdỹỹna-my ijyy reòrarunyre iòraru rbi, timybo axina inyki rèny riórarunyre, irbi tahè tuu nadelyymyhỹde timybo wji bdè-my iny ijoi reny mahãdu axina diwinymyhỹrenyre, tuu tahè ijõ tyyrti-ki nadelyymyhỹde, irbi ramy tasỹihadena-my, aõnaõna iny tai riuhémyhỹre my tule nadelyymyhỹde. Axina bdèdỹỹnana butumy dimymyhỹde, xiwe ijoina-ki riòrarunymyhỹre-u ijoi riwinymyhỹre, ta ijora axina-ki ijoi rohotirakre-my xiwè dóhònymyhỹde-u ijoi isby diwinymyhỹde, ijoi raxiwe rahu-di tahè wyhy delemyhỹde, ta ijora kua rbi hyy ijomy iny denarèhèmyhỹde tuu ijyy ijõdikre, timybo ijoi riwinymyhỹre iny riròkre-my tuu tahè waaõmysydỹỹna raonanany myhỹre iharè rimyrèri iwitxira witxira waxina iteosina; ynyraroo axina, ahu axina, tòla axina teà axina, irbi ne tasỹ ijo raréri, axidè, axidè hatena, aõnaõna iny riuhèmyhỹre axina-ki, xiwè ijoina-ki, xiw’xiwe axina-ki, wyhy bwidyyna, wyhy widyyna-ki aõnaõna iny riuhèmyhỹre, xiwè otuni wdeu, inarehe, axidè, wyhy witxirawitxira, obiu, hetyy, utura dé ỹnydé. Kamahadu tahè waõmysỹdỹỹna-ki tuu ararybe kre, tiiemy tii aonityhy iny riuhe myhỹre axina ki.

RYBÈ WÉRYNA: Iròdu. Axina. Wyhy. Bdèdỹỹnana.

${ }^{1}$ Graduado em Educação Intercultural, habilitação em Ciências da Linguagem, do Núcleo Takinahakỹ de Formação Superior Indígena (NTFSI) da Universidade Federal de Goiás (UFG). Pesquisador da Ação "Saberes Indígenas na Escola”, Rede UFG/UFT/UFMA. Professor da Educação Básica. Escola Estadual Indígena Hawalòra. Aldeia Hawalòra, Santa Terezinha, MT, Brasil. E-mail: bidja2012@gmail.com. 


\section{Pesca colectiva con timbó del pueblo Karajá}

\section{RESUMEN}

El artículo tiene como base el conocimiento oral que se fundamenta en mito, historia y acontecimiento que revelan varios conocimientos, envolviendo la realidad vivida por mi pueblo. Este trabajo es fruto de una investigación que involucra al pueblo Karajá, en general, Karajá del norte y Karajá del sur, y aborda la pesca colectiva con timbó del pueblo Karajá iny axina. También aborda la pesquería, en general, como rezos, rituales, ceremonias y resguardo, principalmente el concepto de pesca dentro del ciclo que ese pueblo sigue, cada pesca en su debido tiempo. El éxito de esta pesca depende de la organización, liderazgo ante este acontecimiento, que tiene como apoyo al jefe de la aldea que también tiene una participación importante en ese acontecimiento en la comunidad Karajá.

PalabRas Clave: Pesquería. Reza. Tradición. Timbó.

\section{Introdução}

Esta pesquisa tem como objetivo a conscientização, revitalização e atualização de alguns ritos que são deixados de lado, na realização da pesca coletiva, com timbó do povo Karajá: iny axina. A escolha desse tema, para ser pesquisado, foi por razões de que a aquisição de materiais e objeto não nativos tem influenciado na convivência da comunidade, impactando no ciclo da vida do povo Karajá, e esse impacto vem fazendo, drasticamente, a mudança que, por um lado, não é benéfico, por não ser nativo.

O ambiente de convivência onde acontece rituais, canto, observação, sigilo é fundamental na natureza. A chegada de tecnologia vem como uma distração para jovens Karajá, assim, tirando a sua atenção da sua aula. Por ser uma pesquisa importante para o povo Karajá, a sua apresentação na comunidade foi de grande relevância, por ser um tema que relata conhecimentos orais, historicamente contados por mais velho ou conhecedores de pescaria do povo, além disso, é relevante também, por ser uma das primeiras documentações da prática da pesca coletiva, com timbó, que ficará como registros fotográfico e escrito, na língua materna do povo Karajá e na língua portuguesa, muito importante para a divulgação dos conhecimentos indígenas e, principalmente, a pesca sustentável que é feita na comunidade indígena. Servirá também como conscientização para a sociedade nacional e para a universidade reverem um pouco a parte intracultural da interculturalidade em relação à publicação do artigo acadêmico indígena. 


\section{Referencial epistêmico}

As informações contidas, nessa pesquisa, de autoria do povo Karajá, são fonte de conhecimento oral, contada e vivenciada pelo povo. Contém importante conhecimento sobre ritos de iniciação de pesca e ao mesmo tempo contém a história sobre o resguardo que envolve amplamente a questão da rigidez dentro da regra envolvendo a tradição. Além dessas informações, há também informações adicionais que também são importantes para o desenvolvimento da pesca. Os principais pontos dessa pesquisa são: o resguardo que é muito importante para que o sucesso na pescaria seja bom; reza, um dos ritos que envolvem a religião própria do povo, que são com aruanã, espírito da natureza, um dos pontos importantes para que esses ritos se realizem; cantos que também entram como ponto importante nessa pesca, tanto na alegria, como também na tristeza. $\mathrm{O}$ canto tem como função a invocação dos espíritos, em geral.

Apesar de esse acontecimento ser do povo Karajá, tive pouca convivência ou de observar um acontecimento de pesca amplamente elaborado por coordenador da pesca, ou seja, dono dessas práticas. Em alguma parte, principalmente de canto, resguardo e reza, em uma espécie de primeira observação, a vida vai mostrar no seu devido tempo o conhecimento que envolve o mundo de uma comunidade, como cacique Waximauri da aldeia Hawalòra fala "a gente vai adquirindo conhecimento no seu devido tempo, ou o tempo vai mostrar como funciona o nosso mundo" disse ele ao jovem. E isso realmente é verdade, pensando nessa pesquisa, o contexto que é mostrado por essa prática, confirma a fala do cacique.

Encontrei pouca informação escrita para que essa pesquisa fosse realizada. Não tinha como base de apoio, a esta pesquisa, um artigo sobre esse assunto que tivesse sido escrito por outro acadêmico, em relação ao povo Karajá. Mas tive a fonte oral que me auxiliou no desenvolvimento dessa pesquisa, principalmente sobre quando era feita, como era realizada, qual era o tipo de flecha a ser usada na pesca. As informações contidas, nessa pesquisa, vêm dos conhecedores dessa prática que, por muitas vezes, vivenciou a prática e relatou informações importantes. Ao mesmo tempo, informações contidas aqui não são apenas de uma aldeia, mas sim de várias, onde se encontram os anciões conhecedores que se fundamentam na base da história, mito, observação dos mais velhos.

A importância do conhecimento indígena, no contexto da interculturalidade, tem o seu benefício tanto como forma de mostrar esse conhecimento para garantir a sua sobrevivência, mas também como forma de conscientização - da sociedade em geral - pois tira um pouco do 
preconceito da soberania da escrita e, também, do poder que a comunicação exerce em relação ao indígena, mostrando um mundo diferente daquele que a gente vive, provocando, assim, uma imagem negativa em relação ao indígena, distorcendo a realidade vivida pelo povo indígena.

A interculturalidade tem como função incentivar o encontro de vários conhecimentos dentro do campo da escrita, por ser mais valorizada em sociedade hierárquica. O caminho indígena, para que seja conhecido da forma que é, para que a sociedade em geral conheça de verdade, é o da interculturalidade, a partir de o próprio autor indígena escrever sobre seu próprio conhecimento. Isso facilita, para maioria do povo indígena, a divulgação de informações verdadeiras em relação a seus conhecimentos.

\section{Bdèdỹ̃̃nana}

A pesquisa utiliza entrevista como método para a transcrição da fala, para poder conhecer um pouco mais da história que existe por trás da pesca. A partir disso, parti para a próxima metodologia para descobrir sobre o assunto dito na primeira pesquisa. Nessa pesquisa, também foi utilizada a metodologia da pesquisa de campo, para facilitar o conhecimento da matéria ou de determinado conteúdo, para que o pesquisador possa conhecer o objeto pesquisado, juntamente com conhecedores da prática da pesca. Para formalizar a documentação também foram feitas gravações, fotos, vídeo, de acontecimento da prática de pescaria. Depois do estudo do conteúdo pesquisado com os conhecedores, procurei assuntos da pesquisa que ficaram vagos, ou seja, que deixaram alguma dúvida em relação à pesquisa.

A participação dos mais velhos, nessa pesquisa, foi de extrema importância para o desenvolvimento do trabalho, partindo do conhecimento oral que tem um valor imenso na comunidade Karajá. Contei com a participação dos conhecedores de outra aldeia, como Asukuala, Sariki Karajá, Ijykia Karajá, Waximauri Karajá, pessoas que colaboraram com essa pesquisa e na realização do meu trabalho. A pesquisa foi realizada na comunidade Karajá, em quatro aldeias, pela sua divisão política tradicional são: Ibòò e Iraru principalmente na aldeia Hawalòra, realizada nos anos de 2014 a 2016. A metodologia adotada contribuiu de maneira significativa na organização do trabalho:

- Pesquisa no campo para colher materiais;

- Entrevista em outras aldeias Karajá; 
- Documentação de várias formas: foto, vídeo, áudio, escrita;

- Realização prática da pesca para observação.

\section{Resultados}

Por ser um conhecimento que vem da convivência da oralidade e história que é contada de pai para filho, trata-se de um conhecimento que as gerações do povo Karajá vêm trazendo desde a sua existência. É uma prática coletiva como forma de educação dos jovens e, ao mesmo tempo, como afirmara os mais velhos, era uma forma de lazer. As pescarias eram feitas para receber gente de outras aldeias, para festa e, também, em visita familiar. Essas pescarias com timbó, feito por povo Karajá, é muito complexa porque envolvem vários outros aspectos da tradição do povo, como festa de aruanã, cantorias como myraasi, entre outros.

\section{1 Prática coletiva}

A relação da natureza com essa prática é marcada em várias modalidades como forma de respeito entre esse mundo, mundo Karajá e o mundo da natureza. Quando um quer entrar no campo do outro, existe rigorosa forma de tratamento que precisa ser seguida. Por essa razão, na maioria da modalidade envolvendo a natureza, vem à coletividade para que a natureza ceda o que a coletividade quer. Em forma de reza, resguardo, canto vem pedir para a mãe natureza e, ao contrário disso, ou seja, a individualidade em campo da natureza, resulta em revolta, isto é, espírito prende espírito do homem para poder mostrar para essa pessoa que nunca uma coisa acontece sozinha. A natureza toma a alma e só é devolvida quando um pajé da comunidade vai fazer um rito para torná-lo pajé, para que possa ver a realidade dentro da natureza e como ela funciona. Por ser um ritual que segue parâmetro de sigilo entre natureza e comunidade ou entre pajé e natureza, a relação entre o mundo onde vivemos e o mundo onde a vida externa é controlada pela natureza, a sua generosidade fica visível com o amor das pessoas da comunidade, com o respeito que carregamos, a maneira como vemos o mundo, fortalece a força que temos hoje em relação a nossa cultura e o mundo espiritual. E a parte coletiva nos fortalece a isso.

A prática envolvendo a pescaria não é diferente. A coletividade prevalece desde o início dos ritos, como mostra a Foto 1 . Na pescaria, em geral, a comunidade se junta para a realização desse ritual. Uma das coisas mais importantes deste começo é a reza, quando os 
pedidos dos homens da comunidade que irão realizar a pesca se junta com a oferenda. Isso acontece na casa dos homens, onde o sigilo dos homens prevalece e, somente quem passa pelo ciclo de formação dos jovens, tem acesso para essa casa. Ijoina, a participação das mulheres, acontece nesse ritual apenas nos resguardos, ou seja, o regime de alguns dos alimentos que não são consumidos durante a pescaria.

Foto 1 - Iny axina.
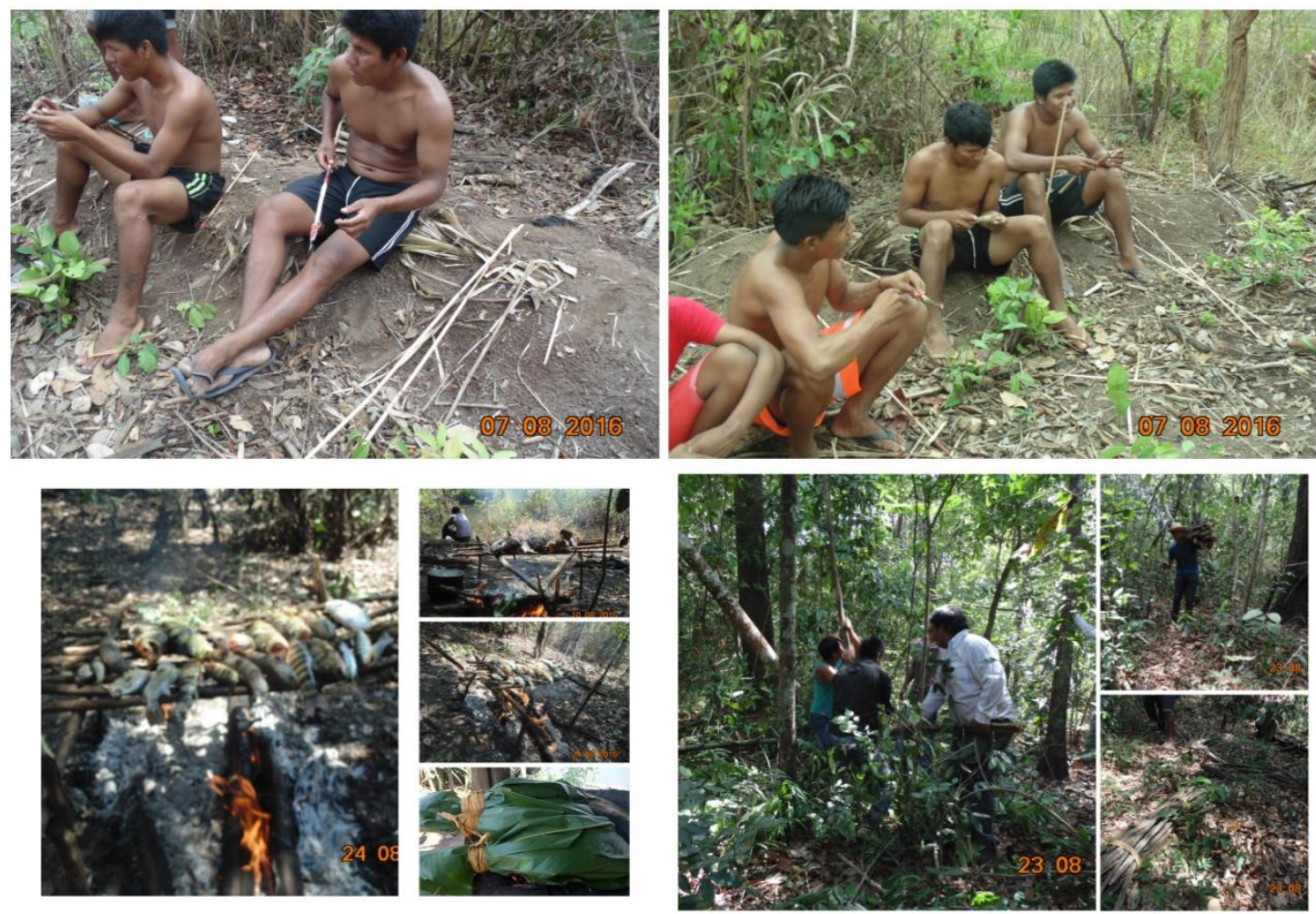

Fonte: Daniel Bidjawari Karajá, 2016.

Um dos pontos principais de partida dessa pesquisa é a coletividade, na qual foi descoberta a prática que já foi deixada de lado. Porém, com essa pesquisa, a pescaria foi atualizada por esse povo.

\subsection{Pontos principais que envolvem a pescaria}

A realização da pescaria envolve uma série de ritos, como por exemplo, a reza, que se inicia quando o dono da pescaria executa uma série de fala, para começar o processo de pescaria. Ali está envolvido o sucesso que essa pescaria coletiva pode ter. O erro na execução 
dessas práticas resulta na falha dessa pescaria. Ao mesmo tempo, o pajé e chefe também farão a sua abertura. A espiritualidade, no mundo Karajá, leva consigo o respeito pela natureza. Para o mundo Karajá, é importante andar em harmonia com o mundo que a gente vive, ou seja, ambiente da natureza local.

O povo segue uma tradição que é respeitada rigorosamente: a restrição de alimento é uma das tradições, pois, em determinada idade da pessoa, têm alimentos que não são consumidos, por razões de que a natureza vai reconhecer o seu respeito perante ela e ela perante você. Isso também vai resultar na saúde da pessoa que fez esse resguardo. Na maioria das pescarias, os jovens que é o público alvo, seguem rigorosamente o resguardo que vai proporcionar a sua liderança e, com isso, uma boa pescaria para seu povo. Um dos destaques para essa pesca, também, é um bom diálogo com a liderança da comunidade, principalmente com o pajé que dará apoio para essa pescaria ser um rito bem sucedido.

Determinada pescaria, realizada apenas pelos pajés e que serve somente para lazer, tem como propósito os jovens terem contato com espírito, dono daquele lugar, que proporciona uma energia na hora da reza realizada pelo pajé. A participação dos nossos jovens é relevante para as pescarias futuras que eles realizarão. A preparação para esses rituais começa desde criança.

A pescaria começa com pouca participação das mulheres. Na reunião, os homens decidem qual material será utilizado para essa pescaria. A quantidade desse material é o pajé quem decide somente depois de sua reza espiritual. De acordo com esse dado repassado pelo pajé para a comunidade, que se começa a cerimônia de busca do material. Depois dessa coleta, o material é levado para o local de pescaria, onde são escolhidos os líderes, as pessoas que irão executar esse ritual. Isso acontece na madrugada, não pode ter presença de pessoas com menstruação, pessoas que tiveram relações sexuais, pessoas que dormiram com a sua esposa. Esse ritual acontece no local da pescaria e é regulado pelo pajé que, por sua vez, identifica as pessoas que estiverem nessas condições, pois elas não podem se aproximar do local do ritual por determinado tempo. Depois de algumas horas de ritual realizado, é liberado para as pessoas fazerem seus acampamentos. Nesse mesmo ritual, depois de o peixe boiar na pescaria, é escolhido o melhor arqueiro para matar peixe, para fazer a reza, para só, então, ser liberada a pescaria do povo. Assim, é liberada a pescaria. Na finalização dessa pescaria, a sua preparação é bem complexa também, porque existem várias maneiras de se preparar o peixe para que sua conserva seja duradora, hetyy, obiu etc. 
Essa lição é carregada por uma pessoa, pelo resto da sua vida e, em determinado tempo, é repassada em forma de história oral para os jovens seguirem. O povo indígena, de maneira geral, tem como ponto forte a agremiação, que é seguir o que seu antepassado repassa para sua comunidade, isso tem como ponto forte o respeito que nós, indígenas, temos pela natureza.

O resultado que essa pesquisa obteve é imensamente importante, por várias razões, por ser um conhecimento pouco praticado, por envolver a natureza na sua realização, pelo respeito ao outro, e a coletividade que é muito importante.

\section{Considerações finais}

O conteúdo dessa pesquisa é muito importante para o povo Karajá e, ao mesmo tempo, também, para a sociedade em geral, por várias razões. O conteúdo que a pesquisa abrange é o fundamento que representa a realidade do povo indígena. E como tratam a natureza no ponto de vista indígena, a convivência do povo com a natureza de forma que conscientizem a sociedade em geral. A sua importância, principalmente para povo Karajá, se deve ao fato de conter conhecimento que parte da historia contada e passa oralmente, como a educação é feita nas comunidades indígenas. E também o conhecimento escrito, como forma de salvaguardar o conhecimento desse povo.

O impacto que essa pesquisa trouxe para essa comunidade é de valor inexplicável, porque contém a história de um povo repassada oralmente, pelos anciões, principalmente o conviver de um povo com a natureza. Isso resulta, também, em bem estar da população Karajá, tanto por convivência de uma nação, ou coletivo onde a natureza educa os jovens, não apenas para povo Karajá, mas também para sociedade nacional. Seguindo essa forma de viver, respeitando a natureza, o convívio respeitando um ao outro, sem exploração, não iríamos sofrer com a mudança vivenciada, hoje, no mundo. Esse trabalho tem uma colaboração muito grande com a educação escolar do meu povo, que impactou, positivamente, inclusive na realização da prática da pescaria. A escola foi uma parceira que dividiu essa experiência, a mudança no calendário escolar que é imposto por não indígena, não seguindo parâmetro de vida do povo Karajá. Essa pesquisa também servirá de apoio pedagógico para outros professores fazerem a sua pesquisa. 
A sociedade não indígena tem muita coisa para aprender com essa pesquisa, principalmente com a coletividade, como por exemplo:

- Respeitar a natureza e explorar de forma sustentável.

- Trabalhar coletivamente sem explorar uns aos outros.

- Usufruir das riquezas que a própria natureza oferece sem destruí-la.

\section{Referência}

KARAJÁ, Waximauri. Conhecimentos Tradicionais Iny. Aldeia Hawalòra, 2017.

Submetido em 28 de abril de 2019.

Aceito em 23 de julho de 2019.

Publicado em 25 de julho de 2019. 